\title{
Los alcaldes de barrio de Jujuy. Entre la colonia y la revolución
}

Dionila Baldiviezo*

Fecha de recepción: 14 de julio de 2020. Fecha de aceptación: 21 de septiembre de 2020

Palabras clave

orden

bien común proceso independentista alcaldes de barrio

\section{Resumen}

El trabajo expone el rol de los alcaldes de barrio en el entramado jurídico-social de la ciudad de Jujuy a comienzos del siglo XIX. Estos auxiliares de justicia fueron agentes clave en el complejo escenario político creado luego de 1810. Su representación estuvo cruzada por funciones que desempeñaron como ordenadores de la vida municipal y agentes intermedios en el proceso electoral en la etapa republicana. Para explicar el accionar de estos jueces durante el proceso revolucionario y la consolidación del nuevo orden intentamos responder las siguientes preguntas: ¿quiénes eran estos alcaldes de barrio?, ¿de dónde provenían?, ¿de qué manera ejercían el cargo? y ¿cómo construyeron su autoridad? Este trabajo dialoga con la historiografía reciente sobre historia social de la justicia, en particular con las investigaciones sobre la justicia municipal periférica, las alcaldías de barrio, como también con los estudios de caso sobre los diferentes territorios del Río de la Plata.

\section{District mayors of Jujuy. Between colony and revolution}

\section{Abstract}

Key words district mayors order common good independence process
This work analyses the role of district mayors in the socio-legal framework of Jujuy city in the early $19^{\text {th }}$ century. These court auxiliaries were key agents in the complex political scenario developed in the territory after 1810 . Their representation was overlapped by the functions they performed as community life organizers and as intermediary agents of the electoral process in the Republican period. In order to explain the judges' actions during the revolutionary process and the consolidation of the new order we have tried to answer the following questions: who were these district mayors?, where did they come from?, how did they perform their role?, how did they build structures of authority? This paper dialogues with the latest historiography about the social history of justice, in particular with studies on peripheral municipal justice, neighborhood mayors, as well as with case studies of different territories in the Río de la Plata region.

* Unidad de Investigación en Historia Regional (UNIHR), Facultad de Humanidades y Ciencias Sociales, Universidad Nacional de Jujuy (UNJu). San Salvador de Jujuy, Argentina. E-mail: dionilabaldiviezo@gmail.com 


\section{Introducción}

La producción historiográfica de los últimos años nos aporta el marco teórico para enfocar este trabajo. ${ }^{1}$ La apertura de los archivos judiciales, policiales y carcelarios motivaron un renovado corpus de trabajos sobre la ley y la justicia (Palacio y Candioti, 2007) y se plantearon interrogantes como, por ejemplo, quiénes determinan lo que es justo e injusto, de qué manera se resuelven los conflictos, quiénes administraban justicia. En esta sintonía debemos decir también que, en los últimos años, han salido a luz estudios de caso para Buenos Aires, Santa Fe, Entre Ríos, Córdoba, Cuyo y Tucumán. ${ }^{2}$ En consecuencia, este trabajo se enmarca precisamente en estos estudios y, en particular, en las investigaciones sobre las alcaldías de barrio; en este sentido seguimos el análisis y los trabajos expuestos por Darío Barriera quién las trabajó historiográficamente y develó las formas de abordaje de los estudios de estos jueces menores (Barriera, 2018: 129-162).

En el marco de la historia social de la justicia, y de todos los avances en el estudio de los jueces existentes en una ciudad, pretendemos mostrar la importancia del rol de los alcaldes de barrio de Jujuy durante el proceso revolucionario, para que nos permita entender el ejercicio del poder local de estos agentes intermedios en un contexto general de incertidumbre y de imprevisión permanente. A tal objeto, consultamos fuentes que provienen de los repositorios provinciales, especialmente del Archivo Histórico de Jujuy y el Archivo de Tribunales de Jujuy. En primer lugar, mencionaremos los antecedentes de estos jueces, seguidamente situaremos a Jujuy en el contexto administrativo colonial y revolucionario y, finalmente, daremos cuenta de la creación y territorialidad de los alcaldes de barrio, sus funciones y su accionar en la ciudad de Jujuy durante el proceso revolucionario. En la redacción utilizaremos alternativamente los términos alcalde de barrio o jueces de cuartel como sinónimos.

\section{Antecedentes}

La figura de los alcaldes de barrio ya existía en la administración española desde 1768 (Marín, 2012) y desde allí fue trasplantada a Hispanoamérica a fines del siglo. Siguiendo los estudios de Brigitte Marín sus antecedentes policíacos se encuentran en el París del último tercio del siglo XVIII, como así también en otras regiones de Europa (Marín, 2012). Estrechamente ligado al origen de estos agentes se encuentra la expresión de "orden público" y de "control social" (Godicheau, 2013: 110), funciones inherentes a los intereses de su origen y expresadas claramente en las instrucciones que recibían una vez nombrados por la autoridad competente en cada lugar.

El antecedente más remoto de las alcaldías de barrio en el Río de la Plata se remonta al año 1734, cuando el gobernador Miguel de Salzedo con el objeto de controlar el orden público y evitar hechos ilícitos entre los pobladores debido a que "frequem. ${ }^{\text {te }}$ se practica la yntroduz. on de Generos de Ylizito comercio en esta dha. Ziudad", ${ }^{3}$ ordenó al cabildo de Buenos Aires dividir la ciudad en barrios y nombrar diputados al frente de ellos. Este ordenamiento no prosperó, tampoco otros que intentaron dividir la ciudad. La división en barrios se formalizó recién en 1772, cuando el virrey Juan José Vertiz fraccionó la ciudad de Buenos Aires en dieciséis barrios y nombró al frente de ellos a comisionados (Barriera, 2018).
1. Por ejemplo, Fradkin (1997, 2007, 2008, 2009), Garavaglia (1997), Barriera (2010, 2012, 2017), Piazzi (2011) y Tío Vallejo, (2012), entre otros.

2. Entre los estudios de caso sobre Buenos Aires están los de Yangilevich (2012), Candioti (2018) y Corva (2018); en Santa Fe los de Piazzi (2011) y Barriera (2018); en Entre Ríos el de Pressel (2018); en Córdoba el de Rustán (2012); en Cuyo los de Molina (2018) y Sanjurjo de Driollet (2018) y en Tucumán el de Tío Vallejo (2011).

3. AGN. Acuerdos del Extinguido Cabildo de Buenos Aires 1929. Serie II, VII: 64 . 
4. AGN. Acuerdos del Extinguido Cabildo de Buenos Aires 1929. Serie IV, IV: 25 .

5. AHJ. SRR, Caja XXXIII, LC, 17811811.

6. Con capital en la ciudad de Salta comprendió además del territorio de Jujuy, San Miguel de Tucumán, Santiago del Estero y Catamarca, a los que se sumarían más tarde Tarija y Orán. (Cfr. Conti, 2002).
7. El cabildo nació con la fundación de la ciudad en 1593 y fue suprimido en 1837 por el gobernador de la provincia, Pablo Alemán.
En la gobernación de Salta del Tucumán las alcaldías de barrio se implementaron en el año 1785 cuando el gobernador Intendente Andrés Mestre ordenó al cabildo de la ciudad de Salta que, además de los oficios capitulares propios de la institución, eligiese alcaldes de barrio (Acevedo, 1965). El objetivo de Mestre fue asegurar la obediencia a las autoridades por parte de los pobladores y evitar así el desorden público (Mariluz Urquijo, 1951). El cabildo salteño dividió entonces a la ciudad en cinco cuarteles, nombró los alcaldes y le dio instrucciones para su funcionamiento. Desde su origen los alcaldes de barrio ejercían funciones de policía en la ciudad: mantenían el orden público, cuidaban de la seguridad, higiene y moral de la población, realizaban además funciones de vigilancia destinadas a prevenir delitos. Eran auxiliares de justicia de los gobernadores y de los alcaldes ordinarios del cabildo.

En el Río de la Plata los alcaldes de barrio eran designados por la corporación vecinal y estaban sujetos a la aprobación del gobernador, pero a partir del año 1805 la corporación tuvo toda la potestad de su nombramiento. ${ }^{4}$ Estaban autorizados a tener bajo su mando tenientes cuya función era auxiliarlos en las tareas, pero su nombramiento le correspondía al cabildo de acuerdo con la propuesta elevada por los alcaldes de cuartel.

Los alcaldes de barrio duraban en su mandato un año. Halperín Donghi sostiene que hasta 1811 el cargo fue vitalicio, después pasó a ser anual (Halperín Donghi, [1972] 2002). En Jujuy, desde su creación en 1808, el cabildo los nombró anualmente. $^{5}$

\section{El territorio de Jujuy, su cabildo y los alcaldes de barrio}

El territorio jujeño pertenecía a la jurisdicción de la Gobernación del Tucumán hasta la Real Ordenanza de Intendentes de 1782, cuando se reordenó la administración territorial de las colonias españolas en el territorio americano. Jujuy quedó entonces alojada dentro de la Intendencia de Salta del Tucumán. ${ }^{6}$ En 1814 por orden del director supremo, Antonio Gervasio de Posadas, la Intendencia se dividió en dos provincias: Tucumán y Salta. Jujuy y su jurisdicción quedaron sujetas a la provincia salteña, dependencia que mantuvo hasta 1834, año en que declaró su autonomía. El territorio jujeño estaba conformado por el curato rectoral y los curatos de la campaña constituidos por: Tumbaya, Rio Negro, Humahuaca, Perico y los cuatro curatos de la Puna: Yavi, Cochinoca, Rinconada y Santa Catalina.

La ciudad de Jujuy y su jurisdicción estaban regidas por su cabildo, institución colonial que tuvo una larga existencia como rectora de la vida política y social de la población. ${ }^{7}$ El territorio jujeño tenía en su seno un entramado de jueces que impartían justicia en nombre del rey, estaba el subdelegado de la Puna que respondía al gobernador de la intendencia y los alcaldes nombrados por el cabildo: los jueces de primer y segundo voto, el juez de aguas; los alcaldes de la santa hermandad, los jueces pedáneos y alcaldes comisionados que actuaban en la campaña. A este contexto jurídico se sumaron dos jueces más: los alcaldes de barrios con jurisdicción en la ciudad de San Salvador, que se encontraba enmarcada por los ríos Grande y Xibi-Xibi, entre cuyas barrancas habitaban las principales familias de Jujuy (Mapa 1). 


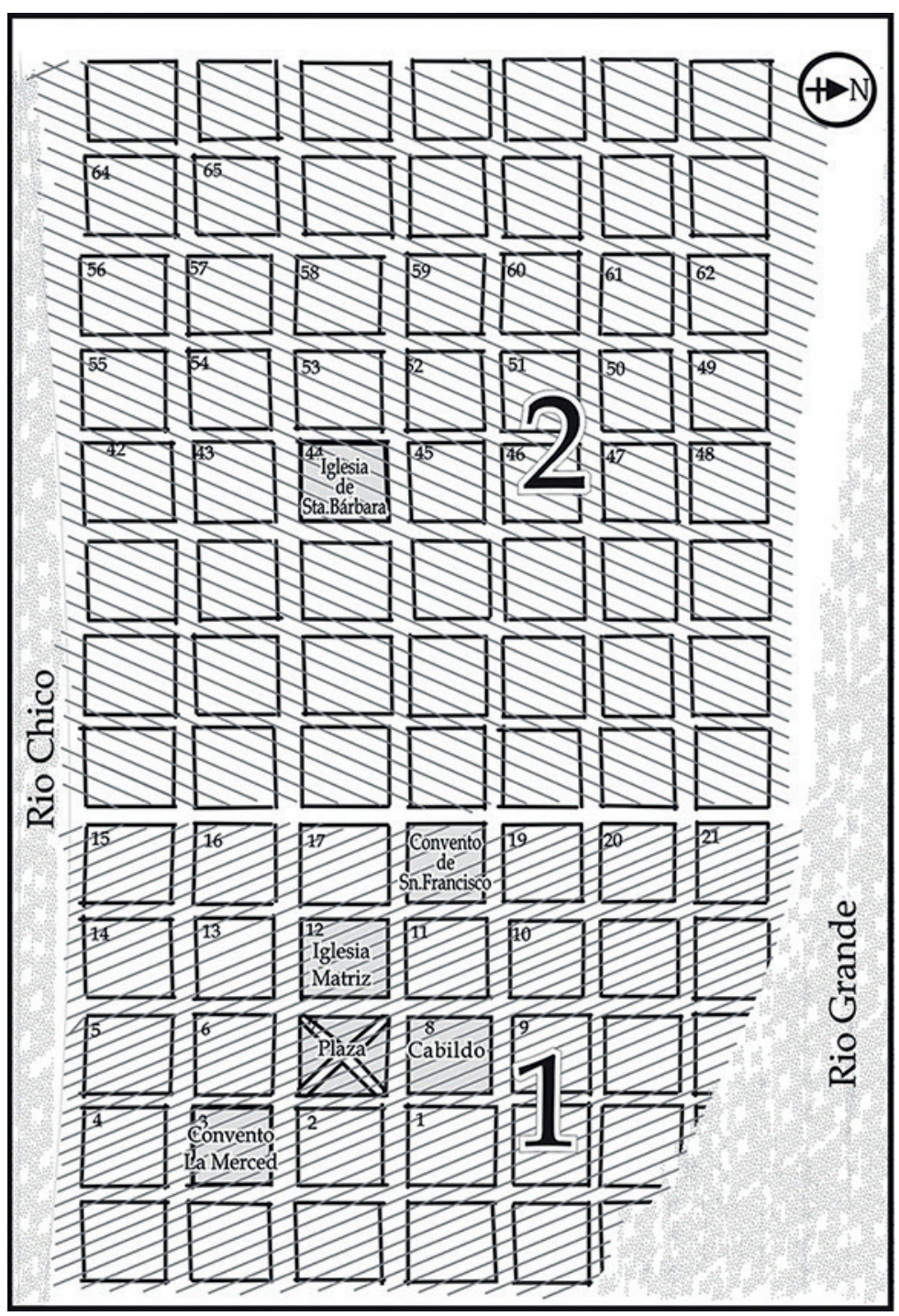

Mapa 1. 1808. Elaboración sobre el Plano de la ciudad de 1808. Fuente: AHP, SRR, Caja 5.

En 1808, el teniente gobernador José de Medeiros instruyó al cabildo de la ciudad para que elija dos alcaldes de barrio con la facultad de resolver pequeñas demandas "hasta una cantidad de doce pesos". ${ }^{8}$ En la reunión del 30 de abril eligieron a los vecinos Andrés Mangudo y José Domingo Velázquez y fijaron la jurisdicción que le correspondía a cada uno. El convento de San Francisco se fijó como punto de referencia para la división de los dos barrios, pero esta partición no conformó a los alcaldes elegidos porque, a los dos meses de su designación, le solicitaron al cabildo instrucciones más precisas acerca de la jurisdicción otorgada como así también sobre las obligaciones que ellos debían cumplir en su rol. Esta demanda obedeció a la resistencia que encontraron en el vecindario para desempeñar sus funciones y también para evitar "desaires públicos de los vecinos y tal vez de los señores alcaldes ordinarios". ${ }^{9}$

La distribución de la ciudad en dos barrios se verá modificada dos años más tarde a consecuencia de los avatares de la vida política, social y militar que atravesó la ciudad desde los acontecimientos revolucionarios en la capital del virreinato.
8. AHJ, SRR, Caja IV, LC: 148.

9. AHJ, SRR, Caja XXXV, Leg. 2, f. 200, AC del 20 de junio de 1808 . 


\section{La revolución en Jujuy y la nueva división de la ciudad}

El proceso revolucionario iniciado en Buenos Aires en 1810 alteró la vida política, económica y social en todo el virreinato del Río de la Plata. Claramente el territorio de Jujuy fue el que más sufrió la ruptura con el rey, puesto que desde 1810 hasta 1825 se convirtió en el epicentro de la guerra de la independencia. Durante quince años los ejércitos de Buenos Aires y Lima ocuparon alternativamente la ciudad y su jurisdicción. Fueron años de sufrimiento y pérdidas para la población jujeña. En este contexto, el cabildo se reacomodó políticamente y respondió a las exigencias de los gobiernos centrales con aprovisionamiento y equipamiento al Ejército Auxiliar del Norte, aprobación de los documentos patrios y organización de los comicios para elegir sus representantes a los congresos centrales (Baldiviezo, 2014).

Con la revolución en marcha los alcaldes de barrio cumplirían un rol fundamental en la convocatoria de los vecinos para que participen en la elección de las nuevas autoridades, y de esa manera otorgarles legalidad y legitimidad a las mismas. En 1811, la Junta de Buenos Aires ordenó a las provincias del exvirreinato "que procedan a elegir los vocales para la junta subalterna que ha de formarse en la ciudad" (en Ravignani, 1939: 4). La convocatoria tenía que ser realizada por los alcaldes de barrio y en el caso de no contar con ellos, o que su número fuere reducido, se subdivida en "seis cuarteles cuando menos" y se designe alcaldes para cada uno de ellos (en Ravignani, 1939: 4).

La circular del 10 de febrero de 1811 ordenaba la elección de dos representantes que integrarían, junto con el teniente gobernador, la junta subalterna de la ciudad. El documento llegó a Jujuy los primeros días de marzo. Entonces el cabildo nombró a tal efecto seis encargados con sus respectivas jurisdicciones, con el objetivo de convocar al pueblo para que elija los electores. Los vecinos nombrados por el cabildo fueron: José Eustaquio Iriarte, Guillermo Marquiegui, Francisco Belasquez, Joaquín Belasquez, Pedro José del Portal y Francisco Menéndez (en Ravignani, 1939: 22).

La distribución territorial de los cuarteles se hizo de la siguiente manera: a Iriarte le correspondió: "desde la Esquina de Don Santiago López hasta la Tablada y Río Chico" (en Ravignani, 1939: 22), en este cuartel votaron veintidós vecinos. El segundo cuartel, a cargo de Marquiegui, estaba circunscripto "desde la Esquina de Don Celedonio Gorriti y la de Don Ramón Sáenz hasta el Pucará" (en Ravignani, 1939: 22); votaron dieciséis vecinos. El sector que correspondió a Francisco Belasquez fue "desde la Esquina de Guerra hasta la Tablada y Río Grande" (en Ravignani, 1939: 23), allí concurrieron diecisiete electores. El cuarto barrio estaba delimitado "desde la Esquina de Don Torcuato Sarverri; hasta el Pucará/ y Río Chico" (en Ravignani, 1939: 23), y fueron nueve vecinos los que concurrieron a votar; a Pedro José del Portal se le asignó "desde la Esquina de San Francisco hasta el Rio Grande y Pucará" (en Ravignani, 1939: 24), asistieron veintiún electores y finalmente el sexto cuartel comprendía "desde la Esquina de Don José Olivera y la de Don Bentura Marquiegui hasta la Tablada" (en Ravignani, 1939: 24), donde votaron dieciocho vecinos. Como observamos, en esta división se tomó como referencia la residencia de los vecinos.

La designación de los comisionados cumplió con el objetivo ordenado. Esta experiencia fue aprovechada por el cabildo que vio la conveniencia de mantener la división de los seis barrios con sus respectivos jueces para intensificar el control y el orden. Esta medida impactó muy bien en la población, puesto que 
la militarización del territorio generaba un constante movimiento de personas que los inquietaba.

El sostenimiento de la nueva partición barrial también respondió al clima de inseguridad que vivía la provincia, pues los rumores de saqueos e invasiones de salteadores y vagabundos motivados por la derrota del ejército patrio en Huaqui generaban el temor del arribo de desertores que huían del fuego enemigo -como así también el temor a la invasión del ejército de Lima. ${ }^{10}$

El cabildo reforzó entonces las instrucciones dadas a los alcaldes de barrio ${ }^{11}$ para evitar posibles disturbios en el vecindario, "[t]endrán especial cuidado de aberiguar y descubrir a los q biertan y siembren especies sediciosas contrarias al Govierno y ó capaces de alterar la quietud pública"12. A la sazón, los barrios quedaron delimitados de la siguiente manera (Mapa 2):

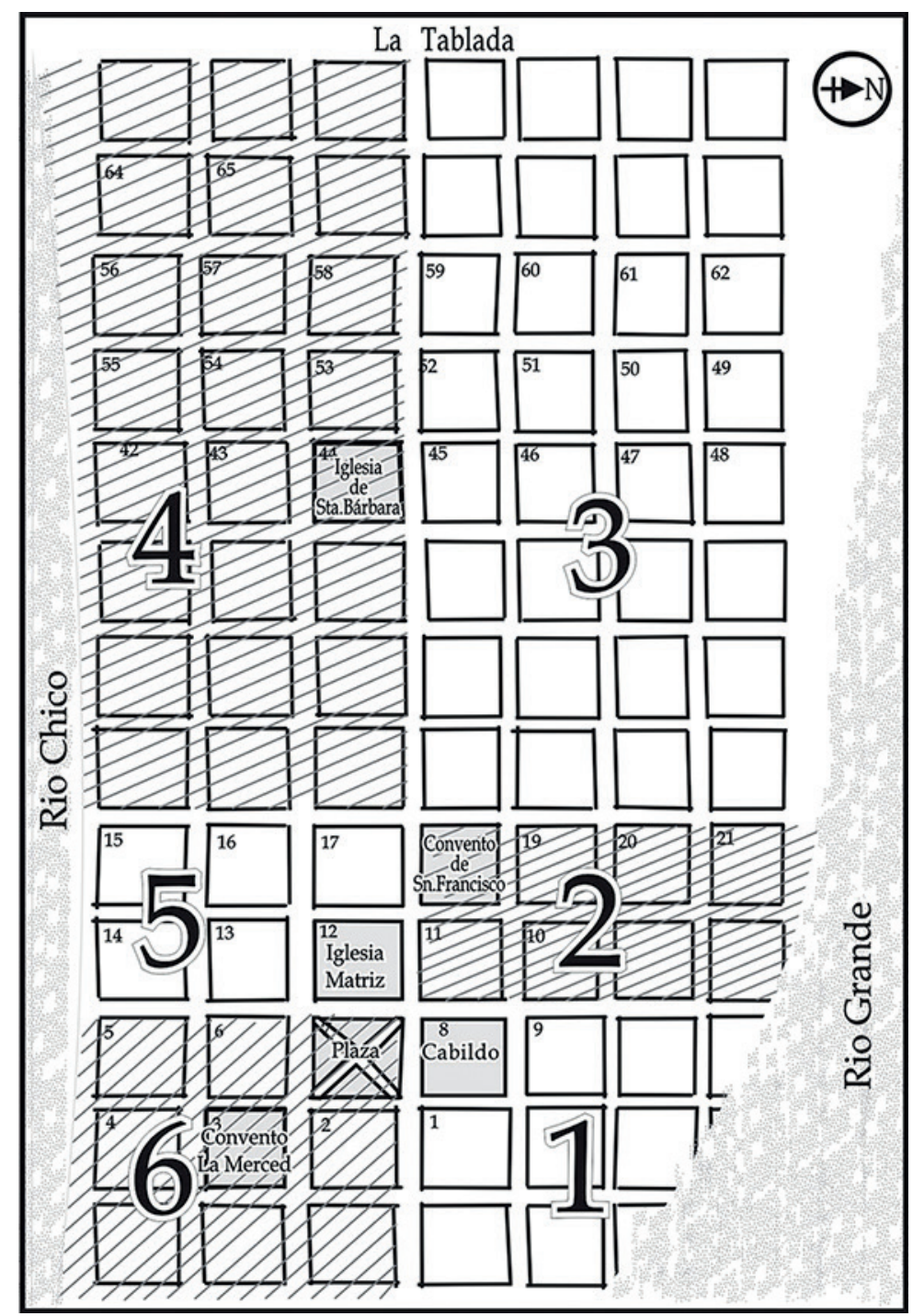

Mapa 2. 1811. Fuente: Gil Montero (1993).

Esta distribución barrial se realizó sobre la base de la división anterior; es decir, que teniendo en consideración la vivienda de los vecinos se realizó la demarcación territorial. Años más tarde este modo de delimitación cambiará
10. AHI, SRR, Caja XXXVII, Leg. 2, f. 267, AC del 9 de septiembre de 1811.

11. Las instrucciones fueron elaboradas por el asesor letrado del cabildo, Teodoro Sánchez de Bustamante.

12. AC del 26 de agosto de 1811 (en Rojas, 1944: 531). 
13. Los cambios obedecieron a los vaivenes políticos y militares que vivió Jujuy durante la lucha por la independencia.

14. AHJ, SRR, Caja XXXVII, Leg. 2, f. 267.

15. Bartolomé de la Corte era pariente del gobernador salteño Martín Miguel de Güemes, la rama familiar proviene de los Goyechea -una de las primeras familias de Jujuy.
16. Las levas eran el reclutamiento obligatorio de la población para servir en el ejército. Eduardo Míguez (2003) sostiene que en algunos casos significaban el desarraigo de los pobladores, quienes cortando sus lazos de propiedad y familia se transformaban de productores de la campaña en soldados desarraigados o desertores. como así también la cantidad de cuarteles. ${ }^{13}$ Los seis alcaldes designados en esta ocasión fueron Pedro José del Portal, Bartolomé de la Corte, José Manuel Alvarado, José Diego Ramos, Francisco Menéndez y Francisco Velázquez, algunos de ellos tenían una alta participación en la sociedad jujeña. Veamos ahora quienes eran estos alcaldes de barrio y sus trayectorias políticas:

José Manuel Alvarado pertenecía a una de las familias más importantes de la elite jujeña, desempeñó distintos cargos en el cabildo entre 1810 y 1821, fue alcalde de primer voto, defensor de pobres, fiel ejecutor y alférez nacional. En 1821 fue ascendido a capitán por Martín Miguel de Güemes, también formó parte de la junta electoral en 1815 y 1826 y representó a Jujuy en la Junta Legislativa salteña en 1830 (Sánchez de Bustamante, 1995: 157).

El alcalde del primer cuartel, Pedro José del Portal, fue defensor de menores en 1810 y muere en 1812. Si bien la familia Portal desempeñó -mucho antes de la revolución- diversos oficios en el cabildo la documentación no nos permite identificar a qué rama de la familia pertenece. ${ }^{14}$

Bartolomé de la Corte, de familia jujeña, se incorporó al ejército patriota, participó en la batalla de Huaqui y en numerosos combates en defensa del territorio jujeño entre 1810 y 1825. Fue alcalde de primer voto en 1819 y en ese mismo año el gobernador de la provincia, Martín Miguel de Güemes, ${ }^{15}$ lo nombró teniente gobernador (Sánchez de Bustamante, 1995: 138).

José Diego Ramos era comerciante, en la emigración ordenada por Manuel Belgrano en 1812 se quedó en la ciudad. Fue también alcalde de la Santa Hermandad en 1813. Francisco Menéndez, fue defensor de menores en 1815 y 1818, miembro de la junta electoral en 1811. Francisco Velázquez alcalde del sexto cuartel, fue fiel ejecutor del cabildo en 1813 y regidor de obras públicas en 1817 (Rojas, 1913: 163).

Como observamos, estos alcaldes provenían de familias consolidadas de la elite jujeña. Tanto los Alvarado, como los Portal o de la Corte tuvieron una amplia trayectoria en la política jujeña a lo largo del siglo XIX, sus parientes fueron diputados en la legislatura jujeña y gobernadores de la provincia.

En 1815 la ciudad quedó reducida a cuatro barrios, quizás la causa sea la disminución de la población. Para 1810 se calcula un total de 12.278 habitantes en la provincia. Especialistas en el tema estiman que entre 1812 y 1823 la merma en la población urbana fue de $25 \%$ (Conti, 2006). Si bien para las zonas rurales no hay datos concretos, se presupone que la pérdida de la población fue profusa por muertes en la guerra, las levas obligatorias como así también por los que huían de ella. ${ }^{16}$ Recordemos que Jujuy fue el cuartel general del ejército patrio, sufrió las invasiones del ejército de Lima y atravesó las emigraciones de 1812, 1814 y 1817. Durante estos años el cabildo se quejaba permanentemente por la falta de vecinos aptos para desempeñar los oficios y, en consecuencia, consideró la posibilidad de que la elección de los jueces barriales se realice cada dos años. Finalmente, en 1816 se formalizó la división de los cuatro cuarteles y la elección de estos agentes fue siempre anual. Para esta segmentación se tomó, como punto de referencia, al igual que en 1808, al convento de San Francisco (Mapa 3). 


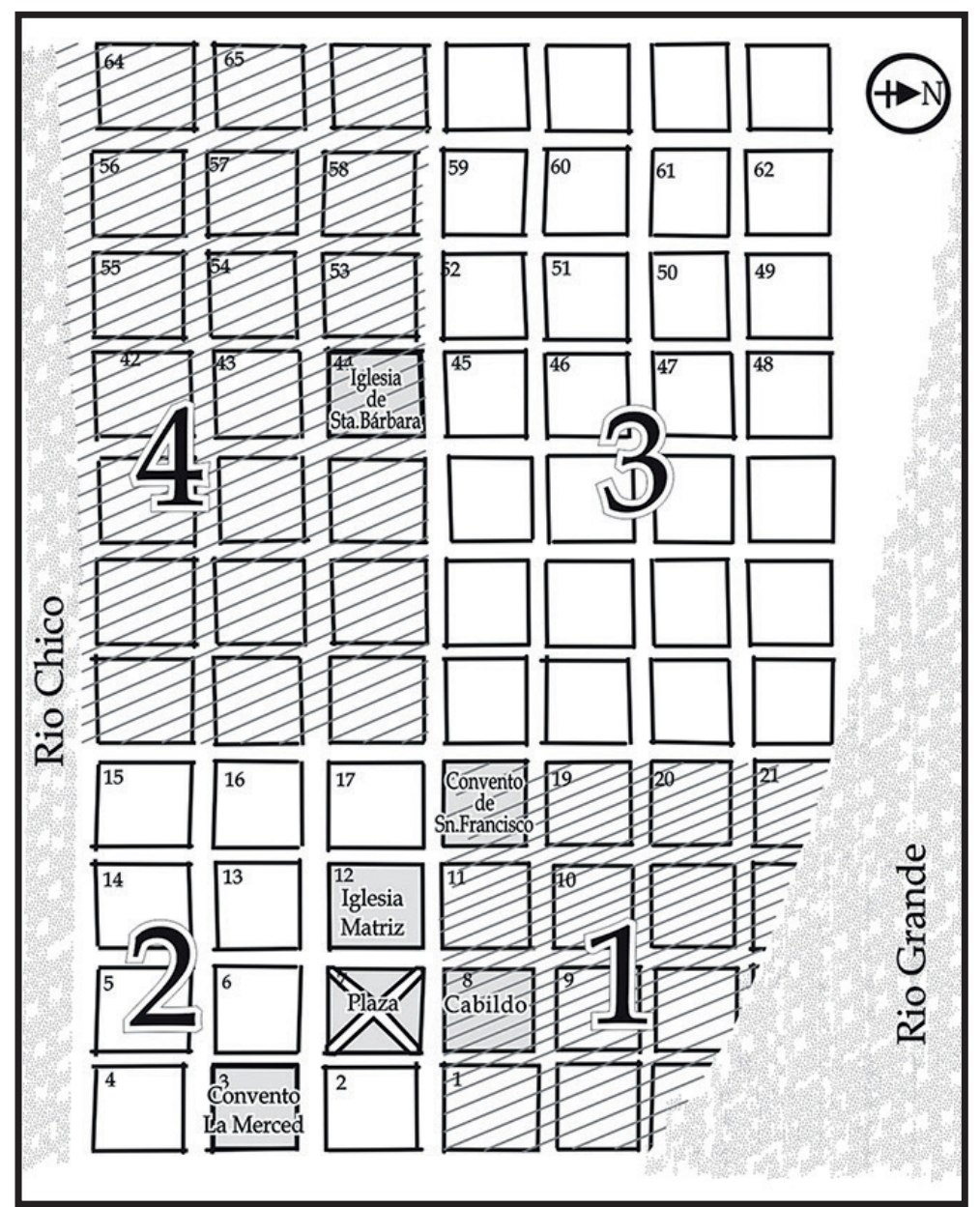

Mapa 3. 1816. Fuente: Gil Montero (1993).

Nuevamente esta demarcación ocasionó controversias a los jueces de barrio, puesto que años después Alejandro Torres, alcalde del primer cuartel, se quejaba ante el cabildo por la falta de numeración que tenían sus jurisdicciones, lo que ocasionaba "confusión y desorden", ${ }_{1}^{17}$ por ello sugiere la delimitación de la siguiente forma: "En la esquina de $\mathrm{d}^{\mathrm{n}}$ Benancio Avila la del Quartel 1o. En la de $d^{n}{ }^{\text {Francisco }}$ Bustamante del $2^{\circ}$. En la de la finada Gogenola la del $3^{\circ}$ y en la de $S^{\text {n }}$ Fran $^{\text {co }}$ la $4^{\circ} \ldots{ }^{\circ} .{ }^{18}$ A juzgar por lo expresado, parecería que esta forma de localización era operativa. En 1830 se combinaron ambas formas; es decir, se tomaron como referencia las instituciones y las propiedades privadas. Los barrios se dividieron de la siguiente manera: el primer cuartel se extendía desde el cabildo hasta el convento de San Francisco, el segundo desde la esquina de la casa de las señoras Mendizábal hasta la Tablada, el tercero desde la esquina de Rosa Isabel de Argañaraz hasta la Tablada y el último barrio desde los tres frentes de la plaza hasta la esquina de Mariano José Saravia. ${ }^{19}$ En adelante esta manera de circunscribir a los cuarteles fue la que finalmente se adoptó. Como observamos en el Mapa 3, los barrios tres y cuatro concentraban la mayor cantidad de vecinos, mientras que el primero era el más reducido pues apenas alcanzaba a dieciocho propietarios.
17. AHJ, SRR, Caja XIV, Leg. 2, f. 167. AC del 31 de enero de 1824 .

18. AHJ, SRR, Caja XIV, Leg. 2, f. 167. AC del 31 de enero de 1824 .

19. AHJ, SRR, Caja XLI, Leg. 1, f. 170. AC del 5 de enero de 1830 . 
20. AC, 26 de agosto de 1811 (en Rojas, 1944: 531-532).

21. AHJ, SRR, Caja XII, Leg. 1, f. 4. AC del 22 de enero de 1820 .

22. AHJ, SRR, Caja XIII, Leg. 3, f. 91, 20 de octubre de 1821.

\section{Los alcaldes de barrio en acción}

Los alcaldes de barrio recibían del cabildo instrucciones que debían observar. Según Mariluz Urquijo las consignas de las disposiciones en Hispanoamérica eran semejantes, en su generalidad, a las otorgadas a los alcaldes de barrio de Madrid en 1768 (Mariluz Urquijo, 1951).

En Jujuy las instrucciones para los alcaldes de barrio de 1811 fueron elaboradas por el entonces asesor del cabildo, Teodoro Sánchez de Bustamante, ${ }^{20}$ las mismas establecían: cuidar el buen orden y la quietud del barrio a su cargo, evitar las borracheras, los juegos prohibidos y celar sobre todo a las juntadas de personas "vagas y mal entretenidas", exigían el pago de multas en caso de alterar el orden y se encargaban del alumbrado de las tiendas y pulperías, la limpieza de las calles y del buen estado de las acequias y empedrados.

Entre sus obligaciones estaban: elaborar un padrón de los vecinos a su cargo, registrando su condición, estado y empleo, estar atentos a la llegada de extraños a la ciudad, inmediatamente debían averiguar su procedencia y dar parte al cabildo si consideraban que el recién llegado era una "persona sospechosa"; es decir, contrario a la causa patria y también tenían la facultad de encarcelarlos y dar parte a los alcaldes ordinarios o al jefe militar.

En los quince años que Jujuy estuvo inmersa en la defensa del territorio frente al avance de las tropas del Perú necesitó del auxilio de los alcaldes de barrio para asegurar el orden, la propaganda revolucionaria y sobre todo para la recaudación de los recursos tan necesarios para sostener la guerra en el territorio. En la organización de la actividad recaudatoria los regidores se asociaban al juez de cuartel para solicitar a la población su contribución, las cuales podían ser voluntarias y en otros casos obligatorias.

Las instrucciones que reciben los alcaldes de barrio en 1811 no sufren grandes modificaciones durante la década. En 1820, se agrega a sus facultades la de entender "en las demandas que no superen los diez pesos y tendrán autonomía para decidir sobre ellas, excepto en las causas militares".${ }^{21}$ Como observamos, tenían facultades para litigar en algunos casos. Al año siguiente la provincia sufrió un gran golpe político, el gobernador Martín Miguel de Güemes fue asesinado por fuerzas enemigas. Este hecho trágico provocó una gran conmoción en la sociedad salto-jujeña y se presagiaban momentos tumultuosos en la provincia (Sola, 1947). Para prevenir posibles disturbios en la ciudad de Jujuy, el entonces alcalde de segundo voto, Andrés Francisco Ramos, endureció las instrucciones dadas a los alcaldes de barrio, quienes debían averiguar la procedencia de la gente extraña a la ciudad, los motivos de su permanencia y su destino final, penando a todos aquellos vecinos que conociendo su existencia no los denunciaban. ${ }^{22}$

La muerte de Güemes provocó una nueva coyuntura política en toda la provincia, marcada ya por una serie de cambios político-administrativos. En 1823, el cabildo reformuló las instrucciones para los alcaldes de barrio, acentuó la jurisdicción que disponían y les recomendó que "debiendo ser primero conocido para ser respetado, no solo en sus respectivos cuarteles sino en toda la ciudad llevasen bastón que los distingue y caracteriza sus personas de día o de noche como lo pide la acción". ${ }^{23}$ Esta recomendación enfatizó las instrucciones dadas por Bustamante en 1811, donde disponía que jurarían ante los funcionarios del cabildo "desempeñar fiel y exactamente el cargo que se les 
confiere" y para que sean conocidos y respetados por tales, "sin que nadie alegue ignorancia", usarán un bastón con puño de marfil o de plata. ${ }^{24}$

No obstante, la preocupación de las autoridades políticas era controlar y disciplinar a los pobladores en sus costumbres e insertarlos en un modo de vida ordenada. En 1821 el teniente gobernador Agustín Dávila sostenía que "no se permite en este Pueblo y su campaña hombres vagos ni mal entretenidos, y su consecuencia el q $\mathrm{q}^{\mathrm{e}}$ e esta clase fuere aprehendido será castigado con cien zotes, y destinado a las armas en un Regimiento de Línea" ${ }^{25}$

En 1828 el teniente gobernador Juan Manuel de Güemes reforzó estas medidas en un bando de gobierno donde consideró las observaciones anteriores y agregó nuevas medidas que debían hacer observar los alcaldes de barrio:

todo hombre que no tenga oficio, ejercicio y destino de que subsistir honestamente cualquiera que sea su seño se conchabará y tendrá en su poder el boleto del patrón que le ocupa [...] bajo la pena de ser reputado por vago y condenado a las obras públicas o nación y sin sueldo. ${ }^{26}$

\section{Protagonistas de la participación ciudadana}

El disciplinamiento de la población y la adhesión al nuevo orden fue vital para la Revolución, los jueces de cuartel fueron, precisamente, los agentes encargados de instruir a los vecinos en la adhesión a los nuevos principios republicanos. En este sentido su rol en la organización de los comicios fue determinante, debían empadronar a todos los vecinos en el registro cívico del cabildo y asegurarse de que todos concurrieran a votar el día establecido. Veamos su participación en la organización del acto eleccionario.

El cabildo notificaba a los jueces de cuartel el día de elección ${ }^{27}$ y les encomendaba que convoquen a sus vecinos a emitir su voto: "se mandaron conbocar los dose Vecinos Electores"; 28 " $\mathrm{q}^{\mathrm{e}}$ los Alc $\mathrm{c}^{\mathrm{s}}$ de Barrio citen a los ciudadanos de sus Quarteles". ${ }^{29}$ Los mecanismos para citarlos fueron a través de los bandos o circulares expuestos en la plaza y en las esquinas más públicas de la ciudad. ${ }^{30}$ Ante la reticencia de los vecinos a concurrir, cuestión que abordaremos más adelante, los alcaldes de barrio comunicaban personalmente; es decir, pasaban casa por casa o donde los encontrasen, notificándolos. Por ejemplo, en 1824, el alcalde del tercer cuartel Juan Manuel Gogenola dejó constancia en el acta de notificación lo siguiente: “En atención a la orden ant ${ }^{\mathrm{r}}$ cite a $\mathrm{D}^{\mathrm{n}}$ Ramón Portal en la Tienda de D ${ }^{n}$ Juan Ignacio Iriarti". ${ }^{31}$

El lugar de votación dependía de la modalidad del acto electoral. En 1810 los electores concurrieron a la sala capitular a emitir su voto por un diputado; es decir, la elección fue en un cabildo abierto y el voto fue directo. A partir de 1815, el lugar de votación fue la casa del alcalde de barrio o de un funcionario del cabildo o -en su defecto- la casa de un vecino, el lugar era determinado con anterioridad por el cabildo. Allí concurrían un funcionario de la corporación, el juez del cuartel y dos testigos en caso de ausencia del escribano. ${ }^{32}$ En estas circunstancias el voto era indirecto pues cada cuartel votaba por un elector. ${ }^{33}$

La elección era a simple pluralidad de sufragios y, como lo señaláramos, la votación podía ser en forma escrita o verbal. Producido el acto electivo los alcaldes del cuartel juntamente con dos testigos se dirigían a la sala capitular con los votos en una jarra, o bien con el resultado de la votación; allí eran
24. AC del 26 de agosto de 1811 (en Rojas 1944: 531-532).

25. AHJ. SRR, Caja XIII, Leg. 2, f. 79.

26. AHJ. CAH, Caja 1828, Leg. 1.

27. A partir de 1810 la actividad electoral se acentuó notablemente en la ciudad, sea para elegir a los representantes a los congresos centrales, los diputados para la legislatura salteña, los alcaldes del cabildo o bien para elegir a los miembros de la junta electoral.

28. AC del 1 de junio de 1812 (en Rojas, 1944: 554).

29. AC del 8 de octubre de 1815 (en Rojas, 1913).

30. Se aplicaba el mecanismo de comunicación de los bandos de gobierno de la colonia.

31. AHJ. SRR, Caja XIV, Leg. 2, f. 205.

32. AHJ. SRR, Caja XXXVI, Leg. 1, f. 540.

33. AC del 28 de octubre de 1815 (en Rojas, 1913). 
34. AHJ. SRR, Caja XIII, Leg. 2, f. 138.

35. AHJ. SRR, Caja XIV, Leg. 2, f. 205. AC, del 22 de abril de 1824 .

36. AHJ. CAH, Caja 1834, Leg. 1, f. 98. recibidos por el teniente gobernador y los funcionarios del cabildo. ${ }^{34}$ Las dos maneras de votación expuestas persistieron en nuestro periodo de estudio, si bien observamos que las urgencias políticas determinaron el lugar y el modo de elección.

La participación ciudadana fue escasa en estos años y así lo demuestran estudios realizados para otros espacios (Ternavasio, 2002). Las autoridades jujeñas también expresaron su preocupación por la poca asistencia en los días de comicios, aspecto que observamos con claridad en un documento de 1824 donde las autoridades del cabildo les comunican a los cuatro alcaldes de barrio que:

Para las 9 de la mañana del sábado 24 del corriente citará a todos los vecinos, estantes y habitantes del cuartel a su cargo a fin de que asistan precisa e indispensablem ${ }^{\text {te }}$ en esta Sala consistorial a Elegir Diputado $q^{\text {e }}$ subrogue al $S^{r}$ D. D. Juan Ignacio de Gorriti en la Representación de esta ciudad para la H.J.P.P. baxo la multa de cuatro $\mathrm{p}^{\mathrm{s}}$ que se les exigirán irremisiblem ${ }^{\text {te }}$ por la falta, a cuyo fin haxa $\mathrm{V}^{\mathrm{s}}$ las citaciones en persona, exigiéndoles la firma a cada individuo. ${ }^{35}$

Diez años más tarde el problema continuaba manifestándose. En esa ocasión tenían que elegir electores para nombrar un reemplazante de José Antonio del Portal en la Junta Provincial: "ha sido citado el Pueblo por 5 ocaciones siendo en la última vajo la multa de cuatro pesos por los Alcaldes de Varrio, mas hta. esta ora que son las doce del dia no se han presentado los principales vecinos". ${ }^{36}$ Los miembros del cabildo se quejaron nuevamente ante el teniente gobernador por esta problemática.

\section{A modo de conclusión}

En este trabajo buscamos mostrar quiénes fueron los alcaldes de barrio de Jujuy y cómo actuaron en un contexto de movilización permanente desde su creación en 1808 hasta el final de la lucha por la independencia en territorio jujeño. En primer lugar, los jueces de cuartel no podían ser abogados, médicos, escribanos, ministros de justicia ni empleados a sueldo por el gobierno. Los jueces de barrio eran magistrados con jurisdicción para conocer y sentenciar sobre los negocios de sus atribuciones; por lo tanto se les debía respetar y obedecer. El territorio de cada cuartel circunscribía su jurisdicción. Eran auxiliares del juez de $1^{\underline{a}}$ instancia ante él, juraban desempeñar bien su cargo y su mandato duraba un año.

En segundo lugar, advertimos que en los primeros años de su existencia el cargo estaba desempeñados por familias tradicionales jujeñas, como los Alvarado, de la Corte, Portal, Sarverri, Puch y Eguren. Entre 1815 y 1821 los alcaldes de barrio eran vecinos que tenían afinidad política con el gobernador Güemes, algunos combatieron con él como Bartolomé Antepara, Juan José Ahumada, José Patricio Puch, Juan Ignacio del Portal, Martín Rojas, José Mariano de Tejerina, Mariano Iturbe, Mariano Saravia y Benancio Ávila, entre otros.

Las familias de la elite jujeña volvieron a ocupar cargos barriales entre 1824 y 1825, allí estaban Alejandro Torres, Ramón Alvarado, Bernardo González, Cirilo Alvarado, Serapio Tezanos Pinto y Joaquín de Echeverría; todos ellos tenían simpatías políticas con el gobernador y el teniente de gobernador, Juan Antonio Álvarez de Arenales y Agustín Dávila. 
En tercer lugar, nos pareció interesante develar su desempeño puesto que las autoridades revolucionarias dependieron de ellos para la convocatoria de la población a las diversas manifestaciones republicanas. En estas actividades no estuvieron ausentes los conflictos ocasionados por la resistencia de los vecinos a cumplir con las órdenes de las autoridades centrales y provinciales. Esta fue la razón del pedido de los jueces de cuartel de una delimitación más precisa de su jurisdicción para tener un mejor conocimiento de los vecinos a su cargo.

La revolución exigió una gran movilización de la población y los alcaldes de barrio fueron actores fundamentales en esta etapa independiente, pues el cabildo recurría a ellos para convocar al pueblo a las asambleas extraordinarias, no sólo para tomar conocimiento de los acontecimientos que ocurrían en la jurisdicción sino también para designar representantes o legalizar la designación de gobernadores. El disciplinamiento de la población y la adhesión al nuevo orden fue vital para la revolución, por ese motivo el cabildo intensificó el sistema de vigilancia de los alcaldes de barrio en la ciudad y los alcaldes pedáneos en la campaña. Por esta razón las atribuciones otorgadas a los alcaldes de barrio se ampliaron durante el periodo de ocupación militar del territorio.

Finalmente, una vez extinguido el cabildo en 1837 los jueces de cuartel se conservaron, en 1845 el gobernador José Mariano Iturbe dispuso:

que los jueces de barrio en la capital i los tenientes jueces en la campaña, deberán tener el tratamiento de comisarios de policía, i funcionar con arreglo a las atribuciones de este cargo, a más de la que le correspondan como a jueces civiles. ${ }^{37}$

En 1851, la provincia sancionó un Reglamento de justicia donde muestra que estos agentes de justicia continuaban en el ordenamiento jurídico de la ciudad. Allí establecía las condiciones para ser alcaldes de barrio: debía recaer en un ciudadano en ejercicio que tenga propiedad o medios conocidos de subsistir decentemente, de buena opinión y fama y mayor de veinticinco años.
37. ROJ “Eugenio Tello” (1885: 192). 


\section{Abreviaturas}

»Archivo General de la Nación (AGN)

» Archivo Histórico de Jujuy (AHJ)

»Serie Ricardo Rojas (SRR)

» Caja Archivo Histórico (CAH)

" Libro Capitular (LC)

»Actas de Cabildo (AC)

\section{- Fuentes citadas}

» Archivo Histórico de Jujuy. Serie Ricardo Rojas, Caja Archivo Histórico

"Archivo General de la Nación (1929). Acuerdos del Extinguido Cabildo de Buenos Aires. Serie II. VII y Serie IV. IV. Buenos Aires, Talleres Gráficos de la Penitenciaría Nacional.

" Registro Oficial de la provincia de Jujuy “Eugenio Tello” (1885). Compilación de Leyes y Decretos por la provincia de Jujuy, Tomo 1: 1835 -1853. Jujuy, Tipografía Libertad de José Petruzzelli.

» Rojas, R. (1913). Archivo capitular de Jujuy, Tomo II. Buenos Aires, Imprenta Coni.

» Rojas, R. (1944). Archivo capitular de Jujuy, Tomo IV. Buenos Aires, Imprenta Coni.

" Ravignani, E. (1939). Asambleas Constituyentes Argentinas seguidas de los textos constitucionales, legislativos y pactos interprovinciales que organizaron políticamente la Nación. Tomo sexto, segunda parte: Pactos, constituciones, leyes, etc. 1810-1898. Buenos Aires, Casa Jacobo Peuser. 


\section{Q Bibliografía citada}

Acevedo, E. (1965). La intendencia de Salta del Tucumán en el virreinato del Río de La Plata. Mendoza, Instituto de Historia, Universidad Nacional de Cuyo.

" Baldiviezo, D. (2014). “El cabildo de Jujuy, 1800-1840”. Tesis de Licenciatura, Facultad de Humanidades y Ciencias Sociales, Universidad Nacional de Jujuy. (Inédita).

»Barriera, D. (coord.) (2010). La justicia y las formas de la autoridad. Organización política y justicias locales en territorios de frontera. El Río de la Plata, Córdoba, Cuyo y Tucumán, Siglos XVIII y XIX. Rosario, ISHIR CONICET.

" Barriera, D. (2012). Justicia de proximidad: pasado y presente, entre la historia y el derecho. Pol-His. Boletín Bibliográfico electrónico del Programa Buenos Aires de Historia Política 10: 50-57. Disponible en Internet: http://historiapolitica.com/datos/boletin/ Polhis10_BARRIERA.pdf. Consultada el: 23 de abril de 2020.

" Barriera, D. (2017). El alcalde de barrio, de justicia a policía (Río de la Plata, 1770-1830. Nuevo Mundo Mundos Nuevos [Online], Debates. Disponible en Internet: https://doi. org/10.400o/nuevomundo.70602. Consultada el: 21 de marzo de 2020.

" Barriera, D. (2018). "Y en el principio, fue la justicia. Las alcaldías de barrio: visibilización de un desenredo en la cultura jurisdiccional (de justicia a 'policía' y nuevamente a justicia, 1772-1861)" en Barriera, D. (dir.); Justicias situadas. Entre el virreinato Rioplatense y la República Argentina (1776-1864): 128-162. La Plata, Universidad Nacional de La Plata, Facultad de Humanidades y Ciencias de la Educación, Instituto de Investigaciones en Humanidades.

"Candioti, M. (2018). “Justicia y legalidad en Buenos Aires. La construcción de la justicia letrada tras la revolución" en Barriera, D. (dir.); Justicias situadas. Entre el virreinato Rioplatense y la República Argentina (1776-1864): 243-262. La Plata, Universidad Nacional de La Plata, Facultad de Humanidades y Ciencias de la Educación, Instituto de Investigaciones en Humanidades.

" Conti, V. (2002). "Salta, Intendencia de" en Diccionario histórico de Bolivia: 828-829. Sucre, Grupo de Estudios Históricos.

》Conti, V. (2006). “De las guerras de la independencia a la organización del Estado 18101852" en Teruel, A. y M. Lagos (dirs.); Jujuy en la historia. De la colonia al siglo XX: 85-137. Jujuy, UNIHR/ EDIUNJu. (Con la colaboración de E. Raspi).

»Corva, M. A. (2018). “El primer ensayo de organización judicial para el Estado provincial de Buenos Aires" en Barriera, D. (dir.); Justicias situadas. Entre el virreinato Rioplatense y la República Argentina (1776-1864): 179-212. La Plata, Universidad Nacional de La Plata, Facultad de Humanidades y Ciencias de la Educación, Instituto de Investigaciones en Humanidades.

" Fradkin, R. (1997). Entre la ley y la práctica: la costumbre en la campaña bonaerense de la primera mitad del siglo XIX. Anuario del IEHS 12: 141-156.

》 Fradkin, R. (2007). Introducción: El poder, la vara y las justicias en Fradkin, R. (comp.); El poder y la vara. Estudios sobre la justicia y la construcción del estado en el Buenos Aires rural, 1780-1830: 9-23. Buenos Aires, Prometeo.

" Fradkin, R. (2008). Cultura política y acción colectiva en Buenos Aires (1806-1829): un ejercicio de exploración en Fradkin, R. (ed.); ¿̇Y el pueblo dónde está? Contribuciones para una historia popular de la revolución de independencia en el Río de la Plata: 27-65. Buenos Aires, Prometeo. 
" Fradkin, R. (comp.) (2009). La ley es tela de araña. Ley, justicia y sociedad rural en Buenos Aires, 1780-1830. Buenos Aires, Prometeo.

" Garavaglia, J. C. (1997). Paz, orden y trabajo en la campaña: la justicia rural y los juzgados de paz en Buenos Aires, 1830-1852. Desarrollo Económico 37 (146): 241-262.

» Gil Montero, R. (1993). “La población de Jujuy entre 1779 y 1869”. Tesis de Licenciatura en Historia, Facultad de Filosofía y Humanidades, Universidad Nacional de Córdoba. (Inédita).

" Godicheau, F. (2013). Orígenes del concepto de orden público en España: su nacimiento en un marco jurisdiccional. Ariadna histórica. Lenguajes, conceptos, metáforas 2: 107-130. Disponible en Internet: https://www.ehu.eus/ojs//index.php/Ariadna/article/view/8959. Consultada el: 15 de marzo de 2019.

" Halperin Donghi, T. ([1972] 2002). Revolución y guerra. Formación de una elite dirigente en la Argentina criolla. Buenos Aires, Siglo veintiuno.

" Mariluz Urquijo, J. (1951). La creación de los alcaldes de barrio en Salta. Boletín del Instituto de San Felipe y Santiago de estudios Históricos de Salta, 23-24: 3-10. Disponible en Internet: https://larramendi.es/catálogo_imágenes/grupo.do?/path=100248. Consultada el: 15 de marzo de 2019.

" Marin, B. (2012). Los alcaldes de barrio en Madrid y otras ciudades de España en el siglo XVIII: funciones de policía y territorialidades. Antropología, Revista interdisciplinaria del INAH 94: 19-31. Disponible en Internet: https://revistas.inah.gov.mex//index.php/ antropologia/article/iew/2696/o. Consultada el: 19 de julio de 2019.

» Míguez, E. (2003). Guerra y orden social en los orígenes de la Nación Argentina 18101880. Anuario del IEHS 18: 17-38.

" Molina E. (2018). “Modalidad de especialización política: de la justicia de proximidad a otras prácticas de agencia gubernamental en Barriales, jurisdicción de Mendoza (18141850)" en Barriera D. (dir.); Justicias situadas. Entre el virreinato Rioplatense y la República Argentina (1776-1864): 99-128. La Plata, Universidad Nacional de La Plata, Facultad de Humanidades y Ciencias de la Educación, Instituto de Investigaciones en Humanidades.

»Palacio, J. y M. Candioti (2007). "Introducción Justicia, política y derechos en América Latina. Apuntes para un debate interdisciplinario" en Palacio, J. M. y M. Candioti (comps.); Justicia, política y derechos en América Latina: 11-24. Buenos Aires, Prometeo.

»Piazzi, C. (coord.) (2011). Modos de hacer justicia. Agentes, normas y prácticas. Buenos Aires, Tucumán y Santa Fe durante el siglo XIX. Rosario, Prohistoria.

»Pressel, G. (2018). "Los alcaldes menores en la Villa del Paraná en la década de 1820" en Barriera, D. (dir.); Justicias situadas. Entre el virreinato Rioplatense y la República Argentina (1776-1864): 163-178. La Plata, Universidad Nacional de La Plata, Facultad de Humanidades y Ciencias de la Educación, Instituto de Investigaciones en Humanidades.

» Rustan, M. (2012). “Jurisdicciones en cuestión. Cabildos y autoridades militares en la administración borbónica. Gobernación Intendencia de Córdoba a finales del siglo XVIII", en Polimene, M. (coord.); Autoridades y prácticas judiciales en el Antiguo Régimen. Problemas jurisdiccionales en el Río de la Plata, Córdoba, Tucumán, Cuyo y Chile: 139-155. Rosario, Prohistoria.

» Sánchez de Bustamante, T. (1995). Biografías Históricas de Jujuy. San Salvador de Jujuy, Universidad Nacional de Jujuy.

»Sola, M. (1947). "Salta (1810-1821)" en Levene, R. (dir.); Historia de la nación argentina (desde los orígenes hasta la organización definitiva en 1862): 365- 401. Buenos Aires, El Ateneo. 
»Sanjurjo de Droillet, I. (2018). “El gobierno del territorio cuyano entre mediados del siglo XVIII y principios del XIX. Los jueces de la jurisdicción de San Juan de la Frontera” en Barriera, D. (dir.); Justicias situadas. Entre el virreinato Rioplatense y la República Argentina (1776-1864): 73-98. La Plata, Universidad Nacional de La Plata, Facultad de Humanidades y Ciencias de la Educación, Instituto de Investigaciones en Humanidades.

» Ternavasio, M. (2002). La revolución del voto. Política y elecciones en Buenos Aires 18101852. Buenos Aires, Siglo veintiuno.

» Tio Vallejo G. (2011) Los historiadores hacen justicia: un atajo hacia la sociedad y el poder en la campaña rioplatense en la primera mitad del siglo XIX. Revista de Historia del Derecho 41:199-212. Disponible en Internet http:///:/Users/usuario1/Downloads/ Dialnet-LosHistoriadoresHacenJusticia-5402652.pdf. Consultada el 3 de abril de 2020

» Tio Vallejo, G. (2012). De bosques perennes y jardines tardíos. El encuentro entre historia política e historia del derecho en las lecturas de una larga transición. PolHis Boletín Bibliográfico Electrónico del Programa Buenos Aires de Historia Política: 58-65. Disponible en Internet: http://historiapolitica.com/datos/boletin/Polhis10_TIOVALLEJO.pdf. Consultada el: 12 de marzo de 2020.

»Yangilevich, M. (2012). "La justicia de paz en la construcción estatal al sur del río Salado (Buenos Aires, $1^{\underline{a}}$ mitad del siglo XIX)" en Piazzi, C. (coord.); Modos de hacer justicia. Agentes, normas y prácticas (Buenos Aires, Tucumán y Santa Fe durante el siglo XIX): 75-92. Rosario, Prohistoria. 